Insight, part of a Special Feature on Programme on Ecosystem Change and Society (PECS): Knowledge for Sustainable Stewardship of Social-ecological Systems

\title{
Nurturing communities of practice for transdisciplinary research
}

\author{
Georgina Cundill $^{1}$, Dirk J. Roux ${ }^{2,3}$ and $\underline{\text { John N. Parker }}^{4,5,6}$
}

\begin{abstract}
Transdisciplinary research practice has become a core element of global sustainability science. Transdisciplinary research brings with it an expectation that people with different backgrounds and interests will learn together through collective problem solving and innovation. Here we introduce the concept of "transdisciplinary communities of practice," and draw on both situated learning theory and transdisciplinary practice to identify three key lessons for people working in, managing, or funding such groups. (1) Opportunities need to be purposefully created for outsiders to observe activities in the core group. (2) Communities of practice cannot be artificially created, but they can be nurtured. (3) Power matters in transdisciplinary communities of practice. These insights challenge thinking about how groups of people come together in pursuit of transdisciplinary outcomes, and call for greater attention to be paid to the social processes of learning that are at the heart of our aspirations for global sustainability science.
\end{abstract}

Key Words: community of practice; transdisciplinarity

\section{INTRODUCTION}

Transdisciplinary research has become a core element of international sustainability agendas, and as a result the formation of cross-sectoral networks and research programs that pursue transdisciplinary outcomes has increased (Hampton and Parker 2011, The Royal Society 2012). This growth is evident in the recent formation of international platforms such as FutureEarth (Rivera-Ferre et al. 2013) and the Program for Ecosystem Change and Society (Carpenter et al. 2012), and has been supported by funding programs such as the International Social Science Council and the Belmont Forum. Central to all such efforts is the coproduction of action-oriented knowledge within diverse groups of scientists, citizens, and policy makers. As transdisciplinary research becomes more embedded in global research practice, it is increasingly important to find ways to enable transdisciplinary teams to work and learn effectively together (Lélé and Norgaard 2005, Norgaard and Baer 2005, Roux et al. 2010).

Several authors have made important contributions toward this end. In their edited volume, Keen et al. (2005) provide a strong argument for a focus on adult learning in groups for sustainability science. These authors highlight the core roles of reflexivity, collaboration, negotiation, integration, and systems thinking in supporting social learning in these contexts. Others have focused more specifically on the processes of knowledge production inherent within transdisciplinary research. For example, Lang et al. (2012) draw attention to processes of knowledge production in situations where academic and nonacademic partners collaborate around a common issue. Based on their analysis, the authors generate a set of design principles, or a step-by-step guide, for transdisciplinary research in sustainability science. Others have highlighted the potential contribution of social theories of learning to understanding knowledge production in transdisciplinary research processes, and have used the concept of "communities of practice" (COPs) to rethink how we understand the goal of knowledge integration in particular (Regeer and Bunders 2003).

In this paper we extend these important contributions by further reflecting on the implications for transdisciplinary research of the concept of COPs. Although Regeer and Bunders (2003) considered the implications of COPs for how we understand knowledge production, we consider the implications of this concept for how transdisciplinary research can be facilitated or nurtured. Much like Keen et al. (2005), we are interested in the broader social dynamics at play in transdisciplinary research teams and draw attention to some important insights that might support better practice. Toward this end, we develop the idea of transdisciplinary COPs in the context of sustainability research.

\section{KEY CONCEPTS}

\section{Transdisciplinarity}

Transdisciplinary research in sustainability aims to overcome knowledge fragmentation with respect to complex socialecological problems. Although the term "transdisciplinarity" can mean many different things (Jahn et al. 2012), its central features in a sustainability context include mutual learning and collaboration among diverse stakeholders, i.e., scientists, citizens, policy makers and resource managers, who are committed to solving complex social-ecological problems (Funtowicz and Ravetz 1993, Gibbons et al. 2004, Russell et al. 2008, Hirsch Hadorn et al. 2010, Mobjörk 2010, Roux et al. 2010). Transdisciplinary research makes science and decision making interactive through the coproduction of knowledge with society (Max-Neef 2005), and success is often deemed to be a function of the degree to which science, management, planning, policy, and practice are interactively involved in issue framing, knowledge production, and knowledge application (Reyers et al. 2010, Roux et al. 2010). The resulting coevolution of understanding and alignment of purpose makes transformational change through transdisciplinary research a real possibility (Pennington et al. 2013). At the very core of all of these features of transdisciplinary research, therefore, is the expectation that people from a variety of backgrounds and interests will learn together through collaborative problem solving and innovation. This has led to an interest in social theories of learning, e.g., the concept of COPs, that might help facilitate these core processes in transdisciplinary research (Regeer and Bunders 2003; Keen et al. 2005).

${ }^{1}$ Department of Environmental Science, Rhodes University, ${ }^{2}$ Scientific Services, South African National Parks, ${ }^{3}$ Sustainability Research Unit, Nelson Mandela Metropolitan University, ${ }^{4}$ Barrett, the Honors College at Arizona State University, ${ }^{5}$ Human and Social Dimensions of Science and Technology, Arizona State University, ${ }^{6}$ National Center for Ecological Analysis and Synthesis, University of California at Santa Barbara. 


\section{Communities of practice}

The concept of COPs reflects a social theory of situated learning that occurs within a web of social relationships and through participation in the world (Wenger 1998). The concept of a COP was originally developed to understand adult learning in apprenticeships (Lave and Wenger 1991), but has since been applied to understanding learning in business, government, large organizations, international development, and the internet (Wenger et al. 2002). A COP, at its simplest, is a group of people who share an interest or a passion for something that they practice, and who learn how to do it better through regular interaction (Wenger 1998). Three features characterize a COP and distinguish it from other groups (Wenger et al. 2002): First, COPs organize around a shared domain of interest. A COP is not just a network of connections between people, e.g., a group of people who work in the same building. COP membership is based on a commitment to the domain of interest and also a shared expertise in that domain. Second, COP members engage in joint activities, helping each other and sharing information. During this process, relationships are built that enable members to learn from one another. In contemporary research settings, most researchers will identify with attending meetings with colleagues, taking new ideas back to their respective institutions, and testing them in projects with students and colleagues before once again sharing their findings. Third, COP members are practitioners and not mere spectators. They actively test ideas, usually through a shared set of resources, e.g., experiences, tools, metaphors, and ways of addressing recurring problems, in ways that enable them to do things better. Developing this sort of shared practice takes time, trust, and sustained interaction.

Importantly, differential levels of participation are an important, and expected, characteristic of COPs (Wenger et al. 2002). A small core group, perhaps $15 \%$ of the whole COP, are expected to be highly active, providing leadership and ensuring that the COP has legitimacy, whereas another roughly $20 \%$ of the COP might be active members who participate regularly but who are not as dedicated or central to the leadership of the COP. The remaining $65 \%$ of a COP are regarded as peripheral, but also critically important because they observe activities in the core and might implement what they learn in other COPs or organizations. Wenger et al. (2002) developed the idea of legitimate peripheral participation as a core aspect of COPs that should be recognized and encouraged.

\section{Transdisciplinary communities of practice}

By its nature, transdisciplinarity is likely to lead to COPs with distinctive characteristics in addition to those described above. Transdisciplinary communities of practice (TDCOPs) are more likely to be distinctly heterogeneous, cross-sectoral groups with a shared interest in and basic commitment to solving complex social-ecological problems. Individuals within these groups will likely engage with one another to coproduce knowledge for practical application and solutions to current challenges, and will be involved in an on-going, iterative process of issue framing, knowledge production, and knowledge application. Adding to their heterogeneity, TDCOP members are likely to operate in substantially different areas of practice, applying their shared knowledge in such varied arenas as science, state institutions, and civil society.
Such TDCOPs can take different forms, emerging from both institutionalized attempts to facilitate transdisciplinary interactions and from self-organizing processes. Here we briefly introduce an example of each type. The case studies were selected because two of the authors (DJR and JNP) have been intensively involved in each of them for a number of years. We will return to these case studies to illustrate the lessons drawn from a synthesis of data, findings, and conclusions based on the primary research of these authors. See Roux and Nel (2013), Parker and Crona (2012), and Crona and Parker (2011) for specific details on these research projects.

The first case study represents an intentionally nurtured TDCOP. The Decision Center for a Desert City (DCDC, founded in 2004) is a university research center designed to facilitate knowledge coproduction between academic researchers, water managers, and policy makers to enhance the efficacy of long-term decision making about water resources under climatic uncertainty in an arid, rapidly urbanizing metropolitan area in the southwestern United States (see Crona and Parker 2011, Parker and Crona 2012). DCDC was designed to be a boundary organization that facilitated transdisciplinary interactions between scientists and policy makers. Boundary organizations are formal organizations designed to exist at the borders of different social worlds, and to broker or mediate interactions between these communities despite their diverse purposes, incongruent values, and potential mutual incomprehension (Guston 2001, Parker and Crona 2012). They are not TDCOPs in and of themselves, but are rather institutional means by which TDCOPs can be catalyzed and fostered. Through a number of specific strategies and concerted efforts, DCDC has facilitated the development of a robust regional TDCOP in which local and regional water policy makers and water resource managers interact to share expertise and collaborate. These heterogeneous, cross-sectoral collaborations have contributed to basic science and to local and regional water policy debates, policies, and practices.

The second TDCOP is a continually self-organizing initiative, referred to here as "the freshwater initiative." Triggered by a onceoff project in 2002 (Roux et al. 2002), a systematic approach to freshwater conservation planning has developed both dynamically and purposefully over the past 12 years in South Africa. Various innovations around assessment methods and demonstration projects were followed by engagement with policy makers from various state sectors (see Roux and Nel 2013). The resulting set of cross-sector policy objectives for freshwater conservation, formulated through a participatory process involving various departments and agencies of national government, acknowledged the systemic nature of water governance and the inherent need for cross-boundary cooperation (Roux et al. 2006). These objectives and an associated quantitative target for freshwater conservation provided the context for a next phase (2007-2011), focusing on identifying priority areas for conservation and exploring institutional mechanisms for their implementation (Audouin et al. 2013). Importantly, this phase followed an action research mode whereby researchers, policy makers, and natural resource managers engaged in mutual learning and actively contributed to a series of products. These products set the scene for the current phase, which is still organizing, with an emphasis on implementation, monitoring, and revision. The core members of this TDCOP have 
shifted over time, depending on the phase of the project and the key objectives at the time.

\section{LESSONS FOR NURTURING TRANSDISCIPLINARY COMMUNITIES OF PRACTICE}

COP theory, together with growing practical experiences with effective TDCOPs, highlights a number of lessons that are not always intuitive for the individuals participating in, managing, or funding transdisciplinary research programs. These lessons relate to (1) purposefully creating opportunities for outsiders to observe the activities of the core group, (2) recognizing that TDCOPs do not exist simply because a group has been created for a specific task, and (3) recognizing that power matters in important ways in the context of TDCOPs.

\section{Lesson 1: Consciously "build benches" for outsiders}

COPs tend to be characterized by a small core group who are very active, with a large group of members on the fringe who participate to a lesser extent, referred to as peripheral participation (Wenger et al. 2002). Opening up opportunities for peripheral participation is important because it creates opportunities for peripheral members to migrate into the core group and therefore expand and replenish membership in this group. Outside of the center and the periphery are people who are not members, but who have an interest in the activities of a community, referred to as "intellectual neighbors" (Wenger et al. 2002:56). Some members will move through all three of these layers over time, at times playing an active role during a given topic or activity and at other times playing a more passive role. Successful COPs encourage peripheral participation and "build benches for those on the side-lines" (Wenger et al. 2002:57).

The DCDC case study offers insight into how such benches can be built in a contemporary transdisciplinary context. DCDC worked to include those on the peripheries of the scientific and water policy communities by holding regular meetings focused on water-related issues, i.e., water briefings, open to all members of the water policy and science community. Free meals were also provided, helping enhance trust by encouraging informal interaction (see Parker and Hackett 2012). Survey data indicate that $62 \%$ of policy makers expanded their ties to the water community as a result of their DCDC affiliation and attendance at water briefings (Crona and Parker 2011). Furthermore, participation in water briefings lowered cultural barriers between researchers and policy makers (Crona and Parker 2012). Overall, water briefings fostered network growth at the peripheries by providing a politically neutral space for persistent interaction, lowering cultural barriers, helping align understanding and interests, and bringing people who were operating on the fringe of the TDCOP into the core group.

The freshwater initiative benefited from continuity in a small leadership group who were the core of the TDCOP, with individual members representing different national agencies with different functions and constituencies. Throughout the lifecycle of the freshwater initiative, and especially during the four-year phase for identifying spatial conservation priorities, the core group actively created opportunities involving a wide spectrum of stakeholders. These opportunities included workshops with practitioners to review delineation of priority areas on maps, involvement of a broader spectrum of scientific disciplines, and small-group meetings with policy officials (Audouin et al. 2013,
Roux and Nel 2013). From this broad-based exposure, some individuals self-selected to become active members of the core group, others did not become active participants but successfully transferred relevant information to their organizations, and still others were less interested or perhaps not equipped or able to take action.

All of these responses represent legitimate and expected behavior for individuals operating at the periphery of a TDCOP. Recognizing this is fundamental to understanding the outcomes of efforts to build benches for intellectual neighbors. Building benches through the means described for both DCDC and the freshwater initiative does not, and cannot be expected to, guarantee involvement in a TDCOP. Viewing these fairly common activities, e.g., workshops and small group meetings, through a COP lens illuminates alternative roles for such strategies in the context of transdisciplinary engagements: These strategies create opportunities for the membership of COPs to be expanded and for ideas to spread beyond the core group. Participation will most likely self-organize based on the degree of excitement and purpose transmitted by the core group; perceptions of salience, credibility, and legitimacy (sensu Cash et al. 2003) offered by the TDCOP; and opportunities offered through bench creation for knowledge sharing and being valued by other members. Importantly, Crona and Parker (2011) show that peripheral individuals who interact with core TDCOP members are more likely to use scientific knowledge produced by the TDCOP in their policy work. In other words, peripheral participation can play an important role in enhancing the reputation of a TDCOP in terms of its perceived credibility, legitimacy, and saliency.

\section{Lesson 2: COPs cannot be artificially created, but they can be nurtured}

Creating a team to work on a problem does not mean that a COP has been created (Roberts 2006), and neither does the creation of a transdisciplinary research project or program. COPs are emergent social phenomena resulting from interactions among diverse groups and stakeholders that must arise out of the concerted efforts and shared interests of the individuals and social groups involved. The conditions that might enable a COP to develop out of such a team over time can, however, be facilitated (Saint-Onge and Wallace 2003), and experience in transdisciplinary practice is showing that it is possible to intentionally create situations that facilitate the emergence of TDCOPs. A relatively successful effort to intentionally nurture TDCOPs is the Fire Learning Network in the United States (Goldstein and Butler 2010). Stakeholder groups have been established at the regional level, and regular meetings are organized by leaders to facilitate dialogue and develop plans, which include both scientist and nonscientist stakeholders. Whereas the multistakeholder groups are focused on consensus building and conflict management, the network of leaders is intended to share knowledge, build expertise, and promote learning. Conditions for frequent face-to-face contact among these leaders and opportunities to implement and test lessons, i.e., practice, are key facilitatory features of this network that have encouraged the development of TDCOPs (Goldstein and Butler 2010).

DCDC used two other primary methods to nurture its TDCOP. First, they created a regional water allocation model acting as a boundary object: WaterSim. Boundary objects are models, classification systems, interactive maps, and so forth that enable 
different communities to interact despite differences (Star and Griesemer 1989). Joint contributions to constructing WaterSim led to greater trust in the model and enhanced efficacy of sectorial interactions (Parker and Crona 2012). Second, they enlisted help from liaisons with experience working in both scientific and policy communities. Liaisons enhanced awareness of DCDC within the water policy community, leading to greater participation, while devising strategies to mitigate conflict and facilitate mutual learning (Crona and Parker 2011, Parker and Crona 2012,).

The aims of the freshwater initiative were explicitly rooted in national water and environmental policies that were products of extensive stakeholder engagement processes and that enjoyed widespread legitimacy in South Africa. Moreover, the main driving organizations of the initiative have the credibility to call meetings and draw participation. These institutional contexts played an enabling role for stakeholder engagement. A specific nurturing approach was to create spaces for, and actively facilitate, collaboration and knowledge exchange across multiple administrative and functional boundaries. Preceding the process of identifying priority areas for conservation, a stakeholder inception meeting was used to classify stakeholders according to their desired level and type of engagement. The initial list of stakeholders included scientists from universities, research councils, museums, and consulting firms, as well as practitioners responsible for protection and management of water resources, biodiversity conservation, land-use management, and integrated development planning. Stakeholders could self-select to participate in various national and regional workshops on issues such as collation and review of input data for spatial planning, identification and review of priority areas, and development of guidelines for the use of priority areas and associated legislative tools in planning and policy processes (Audouin et al. 2013). Furthermore, the freshwater initiative produced products at all levels of Max-Neef's (2005) transdisciplinary hierarchy of knowledge: scientific publications at the empirical level; geographic information system data layers, maps, and implementation guidelines at the pragmatic level; and principles and policy at the normative/value-based level (Audouin et al. 2013). As such, wide-ranging opportunities for involvement were created. With clear learning interdependencies between these various products, practitioners from science, policy, and practice could all feel part of the same overarching TDCOP. As with the DCDC project, maps served as important boundary objects in the freshwater initiative. Participatory mapping, during which scientific information and stakeholder knowledge were integrated, contributed to a sense of legitimacy and inclusive ownership of the final products (spatial conservation priorities).

The insights from both case studies are vital in the context of TDCOPs, which we characterized earlier as likely to be deeply heterogeneous in terms of both the backgrounds of members and their arenas of practice. DCDC tackled the issue of heterogeneity through boundary objects that brought people together and enabled knowledge sharing and partnership building, and by using liaisons with substantial social capital. The fresh water initiative developed products with which all members of the TDCOP could not only identify, but also use and help create through their respective arenas of practice. Being purposeful about the creation of such boundary objects, social relations, and shared products in TDCOPs is essential in a way that one does not find in traditional COPs, in which heterogeneity is less likely. Such heterogeneity brings with it an additional challenge in contexts where TDCOPs are purposefully nurtured: power imbalances.

\section{Lesson 3: Power matters in facilitated TDCOPs}

The notion of learning through COPs holds the possibility of masking the deep power asymmetries that are present in interactions between "experts" and "nonexperts" in transdisciplinary settings (Jahn et al. 2012). Power in this context refers to the differential ability of various subsets within the TDCOP to demand that their needs be met before the needs of others (see Mitchell et al. 1997). Such differences are a particular challenge to efforts to nurture COPs from the outside-in. COPs that develop spontaneously are unlikely to face this challenge, because such power asymmetries would likely prevent the development of such a COP in the first place. Facilitated TDCOPs, however, often involve a wide variety of potential participants and therefore sensitive choices about who is invited to join a given process and who is left out (Mobjörk 2010). Power asymmetries can prevent some actors from playing an active role in a shared endeavor (Mobjörk 2010), and from a COP's perspective, can result in banishing some participants to the periphery with little prospect of joining the core group. Therefore, the first lesson presented by COP theory (lesson 1 above) is also a potentially dangerous one in that it might justify some actors sitting forever on the periphery, or the benches. Therefore, a key goal must be to enable movement in and out of the core over time.

For DCDC, power imbalances significantly challenged colearning and practical deployment of scientific knowledge. DCDC is embedded within a research university and funded via the U.S. National Science Foundation, increasing these stakeholders' ability to demand that their needs be met and skewing its initial research emphasis toward producing highquality basic science (see Parker and Crona 2012). This produced substantial tensions among policy makers and ambivalence about continuing active collaboration. Once having satisfied the university and funding agency, DCDC leaders responded by turning to more practically oriented research and engaging more intensely with water resource managers and policy makers (see Parker and Crona 2012). These dynamics indicate the critical nature of managing power relations and strategic timing for effective functioning of TDCOPs.

Although the core group of the freshwater initiative has been characterized by two or three members who have provided leadership since the inception of the initiative, power dynamics within this group as well as outside have changed based on two factors: First, the initiative evolved along a type of innovation chain from method development to policy formulation to product development to the current implementation phase. The leadership roles of individual members, in part because of the mandates of the organizations that they represented, tended to differ in different phases. Someone with a research mandate would play a more directive role during the developmental phase, whereas someone with a policy mandate might be the key facilitator of interdepartmental deliberations during the policy phase. Second, the initiative functioned like an informal program consisting of loosely connected projects that all contributed to the overall aim of effective freshwater conservation. Some of these contributing 
projects were planned as part of the initiative, and the coexistence of others was of a more serendipitous nature. These projects provided key input during different phases of the freshwater TDCOP, and accordingly the influence of these project teams varied on a needs basis.

Both case studies suggest that power imbalances played a role in the performance of the TDCOPs and that challenges in this regard were dealt with as issues arose, rather than purposefully through foresight. The DCDC case study, in particular, highlights the need to be mindful and strategic regarding how power imbalances are managed, in the absence of which some TDCOP members are likely to withdraw from the process. Maintaining a diversity of parties at the core of a TDCOP is a major challenge, and requires attention to the power and interests of all groups and members.

\section{CONCLUSIONS}

Global sustainability science is experiencing a ground shift, from small, relatively isolated scientific research projects to deeply transdisciplinary work requiring diverse sets of stakeholders to share knowledge, test solutions, and learn together over time. We have shared just one social theory of learning, i.e., COPs, that can enhance our understanding of how such groups operate and how they might be nurtured. Far greater attention to the social processes that underpin collaborative research effort in general will be required in the years to come if the goals of transdisciplinary sustainability research are to be met.

Although previous work highlighted processes of knowledge production and integration in the context of transdisciplinary sustainability science (Regeer and Bunders 2003, Lang et al. 2012), we took a broader view and highlighted practical lessons that emerge from COP theory for how TDCOPs can be nurtured. Such lessons are relevant to researchers, funding agencies, and project managers alike. In some ways, the lessons challenge conventional wisdom about how groups of stakeholders come together and seek transdisciplinary outcomes. Building benches for outsiders particularly challenges a tendency among scientists to keep new ideas to themselves until they are published. Allowing outsiders to observe, learn from, and share new knowledge generated at the core of a TDCOP is likely to be deeply challenging for many scientists. In addition, the fact that TDCOPs do not exist simply because a project with multiple stakeholders is funded challenges project leaders to act and think differently about how such TDCOPs can be nurtured after such a project has been funded or formed. Paying attention to power relations when this is achieved is equally important. Another challenge is that research is largely driven by contracts with fixed budgets and time frames. Many of the enabling conditions associated with TDCOP formation, e.g., trust building, peripheral participation, and selforganization, do not lie comfortably with project management practices. Even when a TDCOP benefits from a large portfolio of individually funded projects, some of the social dynamics are likely to happen in between formal and funded project spaces.

Research on heterogeneous, highly creative, and influential professional communities, networks, and groups in fields as diverse as art, science, and politics is showing that social interactions fostering deep emotional commitment to the group and its ideas and practices are crucial for innovation and performance (Collins 1998, Farrell 2001, Medema 2011, Parker and Hackett 2012). This and other research on collaboration, learning, and creativity should be integrated with that on TDCOPs to extend our understanding of best practices in those increasingly important associations. Both cases described here suggest that TDCOPs may be multilayered, with a core group that provides an umbrella community in which smaller self-organizing COPs, whether transdisciplinary or not, can see the larger significance of their specific practice. Transdisciplinary practice may thus also challenge traditional conceptions of COPs and how they operate, and provide an impetus for re-examining models of COP theory in this context.

Responses to this article can be read online at: http://www.ecologyandsociety.org/issues/responses. $\mathrm{php} / 7580$

\section{Acknowledgments:}

The authors wish to acknowledge the members of the Southern African Programme on Ecosystem Change and Society for stimulating discussion about the role of communities of practice in that network, and for partially funding two meetings at which ideas for this paper were developed. GC wishes to acknowledge that this work is based on research supported in part by the National Research Foundation of South Africa (grant numbers 93446 and 90694).

\section{LITERATURE CITED}

Audouin, M., R. Preiser, S. Nienaber, L. Downsborough, J. Lanz, and S. Mavengahama. 2013. Exploring the implications of critical complexity for the study of social-ecological systems. Ecology and Society 18(3): 12. http://dx.doi.org/10.5751/ES-05434-180312

Carpenter, S. R., C. Folke, A. Norström, P. Olsson, L. Schultz, B. Agarwal, P. Balvanera, B. Campbell, J. Castilla, W. Cramer, et al. 2012. Program on ecosystem change and society: an international research strategy for integrated social-ecological systems. Current Opinion in Environmental Sustainability 4:134-138. http://dx.doi. org/10.1016/j.cosust.2012.01.001

Cash, D. W., W. C. Clark, F. Alcock, N. M. Dickson, N. Eckley, D. H. Guston, J. Jäger, and R. B. Mitchell. 2003. Knowledge systems for sustainable development. Proceedings of the National Academy of Sciences of the United States of America 100 (14):8086-8091. http://dx.doi.org/10.1073/pnas.1231332100

Collins, R. 1998. The sociology of philosophies. Harvard University Press, Cambridge, Massachusetts, USA.

Crona, B. I., and J. N. Parker. 2011. Network determinants of knowledge utilization: preliminary lessons from a boundary organization. Science Communication 33(4):448-471. http://dx. doi.org/10.1177/1075547011408116

Crona, B. I., and J. N. Parker. 2012. Learning in support of governance: theories, methods, and a framework to assess how bridging organizations contribute to adaptive resource governance. Ecology and Society 17(1): 32. http://dx.doi. org/10.5751/ES-04534-170132

Farrell, M. 2001. Collaborative circles: friendship dynamics and creative work. University of Chicago Press, Chicago, Illinois, USA. 
Funtowicz, S. O., and J. R. Ravetz. 1993. Science for the postnormal age. Futures 25(7):735-755. http://dx.doi.org/10.1016/0016-3287 (93)90022-L

Gibbons, M., C. Limoges, H. Nowotny, S. Schwartzman, P. Scott, and M. Trow. 1994. The new production of knowledge: the dynamics of science and research in contemporary societies. Sage, London, UK.

Goldstein, B. E., and W. H. Butler. 2010. The U.S. Fire Learning Network: providing a narrative framework for restoring ecosystems, professions, and institutions. Society \& Natural Resources 23(10):935-951. http://dx.doi.org/10.1080/08941920903012494

Guston, D. H. 2001. Boundary organizations in environmental policy and science: an introduction. Science, Technology, \& Human Values 26(4):399-408.

Hampton, S. E., and J. N. Parker. 2011. Collaboration and productivity in scientific synthesis. BioScience 61(11):900-910. http://dx.doi.org/10.1525/bio.2011.61.11.9

Hirsch Hadorn, G., C. Pohl, and G. Bammer. 2010. Solving problems through transdisciplinary research. Pages 431-452 in R. Frodeman, J. T. Klein, and C. Mitcham, editors. The Oxford handbook of interdisciplinarity. Oxford University Press, Oxford, UK.

Jahn, T., M. Bergmann, and F. Keil. 2012. Transdisciplinarity: between mainstreaming and marginalization. Ecological Economics 79:1-10. http://dx.doi.org/10.1016/j.ecolecon.2012.04.017

Keen, M., V. Brown, and R. Dyball, editors. 2005. Social learning in environmental management: towards a sustainable future. Earthscan, London, UK.

Lang, D. J., A. Wiek, M. Bergmann, M. Stauffacher, P. Martens, P. Moll, M. Swilling, and C. J. Thomas. 2012. Transdisciplinary research in sustainability science: practice, principles, and challenges. Sustainability Science 7(1):25-43. http://dx.doi. org/10.1007/s11625-011-0149-X

Lave, J., and E. Wenger. 1991. Situated learning: legitimate peripheral participation, Cambridge University Press, Cambridge, UK. http://dx.doi.org/10.1017/CBO9780511815355

Lélé, S., and R. B. Norgaard. 2005. Practicing interdisciplinarity. BioScience 55(11):967-975. http://dx.doi.org/10.1641/0006-3568 (2005)055[0967:PI]2.0.CO;2

Max-Neef, M. A. 2005. Foundations of transdisciplinarity. Ecological Economics 53(1):5-16. http://dx.doi.org/10.1016/j. ecolecon.2005.01.014

Medema, S. G. 2011. Public choice and the notion of creative communities. History of Political Economy 43(1):225-246. http:// dx.doi.org/10.1215/00182702-2010-049

Mitchell, R. K., B. R. Agle, and D. J. Wood. 1997 Toward a theory of stakeholder identification and salience: defining the principle of who and what really counts. Academy of Management Review 22(4):853-886. http://dx.doi.org/10.2307/259247

Mobjörk, M. 2010. Consulting versus participatory transdisciplinarity: a refined classification of transdisciplinary research. Futures 42:866-873. http://dx.doi.org/10.1016/j.futures.2010.03.003
Norgaard, R. B., and P. Baer. 2005. Collectively seeing complex systems: the nature of the problem. BioScience (55)11:953-960. http://dx.doi.org/10.1641/0006-3568(2005)055[0953:CSCSTN]2.0. $\mathrm{CO} ; 2$

Parker, J., and B. Crona. 2012. On being all things to all people: boundary organizations and the contemporary research university. Social Studies of Science 42(2):262-289. http://dx.doi. org/10.1177/0306312711435833

Parker, J. N., and E. J. Hackett. 2012. Hot spots and hot moments in scientific collaborations and social movements. American Sociological Review 77(1):21-44. http://dx.doi.org/10.1177/0003$\underline{122411433763}$

Pennington, D. D., G. L. Simpson, M. S. McConnell, J. M. Fair, and R. J. Baker. 2013. Transdisciplinary research, transformative learning, and transformative science. BioScience 63:564-573. http://dx.doi.org/10.1525/bio.2013.63.7.9

Regeer, B. J., and J. F. G. Bunders. 2003. The epistemology of transdisciplinary research: from knowledge integration to communities of practice. Interdisciplinary Environmental Review 5(2):98-118. http://dx.doi.org/10.1504/IER.2003.053901

Reyers, B., D. J. Roux, R. M. Cowling, A. E. Ginsburg, J. L. Nel, and P. O'Farrell. 2010. Conservation planning as a transdisciplinary process. Conservation Biology 24(4):957-965. http://dx.doi.org/10.1111/j.1523-1739.2010.01497.X

Rivera-Ferre, M. G., L. Pereira, T. Karpouzoglou, K. A. Nicholas, S. Onzere, W. Waterlander, F. Mahomoodally, A. Vrieling, F. D. Babalola, C. C. Ummenhofer, et al. 2013. A vision for transdisciplinarity in future earth: perspectives of young researchers. Journal of Agriculture, Food Systems and Community Development 3(1):249-260. http://dx.doi.org/10.5304/jafscd.2013.034.031

Roberts, J. 2006. Limits to communities of practice. Journal of Management Studies. 43(3):623-639. http://dx.doi.org/10.1111/ j.1467-6486.2006.00618.x

Roux, D., F. de Moor, J. Cambray, and H. Barber-James. 2002. Use of landscape-level river signatures in conservation planning: a South African case study. Conservation Ecology 6(2): 6. [online] URL: http://www.consecol.org/vol6/iss2/art6/

Roux, D. J, and J. L. Nel. 2013. Review: freshwater conservation planning in South Africa: milestones to date and catalysts for implementation. Water SA 39(1):151-164. http://dx.doi. org/10.4314/wsa.v39i1.15

Roux, D. J., K. H. Rogers, H. C. Biggs, P. J. Ashton, and A. Sergeant. 2006. Bridging the science-management divide: moving from unidirectional knowledge transfer to knowledge interfacing and sharing. Ecology and Society 11(1): 4. [online] URL: http:// www.ecologyandsociety.org/vol11/iss1/art4/

Roux, D. J., R. J. Stirzaker, C. M. Breen, E. C. Lefroy, and H. P. Cresswell. 2010. Framework for participative reflection on the accomplishment of transdisciplinary research programs. Environmental Science \& Policy 13:733-741. http://dx.doi. org/10.1016/j.envsci.2010.08.002

Russell, A. W., F. Wickson, and A. L. Carew. 2008. Transdisciplinarity: context, contradictions and capacity. Futures 40(5):460-472. http://dx.doi.org/10.1016/j.futures.2007.10.005 
Saint-Onge, H., and D. Wallace. 2003. Leveraging communities of practice for strategic advantage. Butterworth Heinemann, London, UK.

Star, S. L., and J. R. Griesemer. 1989. Institutional ecology, 'translation' and boundary objects: amateurs and professionals in Berkeley's Museum of Vertebrate Zoology, 1907-39. Social Studies of Science 19(3):387-420. http://dx.doi.org/10.1177/030$\underline{631289019003001}$

The Royal Society. 2011. Knowledge, networks and nations-global scientific collaboration in the 21 st century. The Royal Society, London, UK.

Wenger, E. 1998. Communities of practice: learning, meaning and identity. Cambridge University Press, Cambridge, UK. http://dx. doi.org/10.1017/CBO9780511803932

Wenger, E., R. McDermott, and W. Snyder. 2002. Cultivating Communities Of Practice: A Guide To Managing Knowledge. Harvard Business School Press, Cambridge, Massachusetts, USA. 